Esta obra está bajo una Licencia Creative Commons Atribución-NoComercial-Compartirlgual 4.0 Internacional

(c) (1) (8) ()

Validación de materiales gráficos en el Programa Nacional del Cáncer de Mama

Verónica Becerro

DOI: https://doi.org/10.24215/16696581e268

\title{
Validación de materiales gráficos en el Programa Nacional del Cáncer de Mama
}

\section{Graphic materials validation in the National Breast Cáncer \\ Program}

\section{Verónica Becerro veroebc@gmail.com}

http://orcid.org/0000-0002-8286-3912

Facultad de Periodismo y Comunicación Social; Universidad Nacional de La Plata, Argentina

\section{Resumen}

La presente investigación se inscribe en la línea de Investigación Social en Cáncer y se realizó en el marco de la beca de investigación en cáncer otorgada por el Instituto Nacional del Cáncer (INC) y desarrollada entre 2018 y 2019. Esta investigación buscó describir, analizar y validar 
con mujeres entre 35 y 75 años de Berisso y La Plata (Provincia de Buenos Aires) los mensajes producidos por el Programa Nacional de Cáncer de Mama (PNCM) en soportes impresos y digitales con lenguaje gráfico y cuyos propósitos son informar y sensibilizar a mujeres sobre la detección temprana del cáncer de mama.

Palabras Clave: validación, comunicación, cáncer de mama, materiales gráficos.

\section{Abstract}

The current research line up with Cancer Social Studies and was supported by a research scholarship granted by the National Institute of Cancer (INC) and conducted between in 20182019. Our aim was to describe, analyze and test the messages produced by the Breast Cancer National Program (PNCM) with women aged 35 to 75, either in printed and digital supports and with graphic languages supposed to inform and raise women awareness on early detection of breast cancer.

Keywords: communication, validation, breast cancer, graphic materials.

\section{Introducción}

El cáncer de mama es una enfermedad causada por la multiplicación anormal de las células de la mama que forman un tumor maligno. Es un problema importante para la salud de las mujeres argentinas ya que, según el informe del Programa Nacional de Cáncer de Mama (PNCM), es la primera causa de muerte por tumores en mujeres, produciéndose 5600 muertes anualmente. Estiman, además, que se prevén 19.000 nuevos casos por año, lo cual representa el $16,8 \%$ del total de incidencia de cáncer en Argentina.

Se trata de una enfermedad que afecta mayoritariamente a mujeres de entre 50 y 69 años de edad; se reconocen que los principales factores que aumentan el riesgo de enfermar son (1) superar los 50 años; (2) tener antecedentes personales y/o familiares de mama; (3) tener antecedentes personales de enfermedades benignas de mama; (4) haber realizado tratamientos con hormonas o con radioterapia dirigidos a la mama; (5) haberse producido la 
menstruación a temprana edad; (6) tener una edad avanzada en el momento del primer parto; y (7) nunca haber tenido hijos. El cáncer hereditario representa alrededor del 5-10\% de todos los casos de cáncer de mama.

Dentro Instituto Nacional del Cáncer (INC), perteneciente a la Secretaría de Gobierno de Salud y Desarrollo Social, se desarrolla el PNCM, el cual busca que en Argentina las mujeres tengan un acceso equitativo al cuidado continuo, integral, adecuado y oportuno del cáncer de mama, para disminuir su incidencia y su tasa de mortalidad. EI PNCM plantea los siguientes objetivos: (1) asegurar la calidad de los servicios de detección temprana, diagnóstico y tratamiento; (2) establecer un sistema de información estratégica que incluya la vigilancia epidemiológica, el monitoreo y evaluación de la calidad y del impacto del programa; (3) establecer sistemas eficientes de referencia y contra-referencia que aseguren el correcto y oportuno diagnóstico y tratamiento de las mujeres con CM detectadas; (4) fortalecer el trabajo de los registros regionales de cáncer, implantando las medidas necesarias para conseguir la adecuada validez y exhaustividad de los datos obtenidos; y (5) lograr una cobertura de tamizaje que supere el $70 \%$ de la población objetivo.

Las líneas de acción del programa se basan en los ejes del Diagnóstico de situación realizado por el equipo en 2010. Estos ejes son: control de calidad, monitoreo y cobertura. El eje que justifica y al que pretende aportar esta investigación es el de cobertura, que refiere a la capacidad que tiene un programa para llegar a la gente que lo necesita. Como afirma la Coordinación del PNCM, la mayor parte de las mujeres sabe que tiene que cuidar su salud, pero no todas tienen las mismas oportunidades de hacerlo. En este sentido, el programa debe trabajar en pos de eliminar las barreras que impiden el acceso a la cobertura como la falta de información, la falta de tiempo, la sobrecarga por trabajo, hijos, familiares a cargo, la falta de dinero para llegar al hospital y las diversas complicaciones para acceder a las prestaciones del servicio de salud. Con este objetivo, se desarrollan diferentes estrategias de comunicación y sensibilización sobre el CM destinadas a informar a la población y fortalecer a las mujeres con respecto al cuidado de su salud.

El presente estudio se inscribe en la línea de Investigación Social en Cáncer y se realizó en el marco de la beca INC para estudiantes avanzados/as durante 2018 y 2019. Esta investigación fue dirigida por Daniela Bruno y co-dirigida por Flavia Demonte, y buscó describir, analizar y validar con mujeres entre 35 y 75 años los mensajes producidos por el Programa Nacional de Cáncer de Mama (PNCM) en soportes impresos y digitales con lenguaje gráfico cuyos propósitos son informar y sensibilizar a mujeres sobre la detección temprana del cáncer de mama. Para ello, se consensuaron con el PNCM los siguientes objetivos específicos: (1) Describir el proceso de producción de los materiales gráficos en términos de objetivos, 
audiencias, mensajes clave y propuesta estética; (2) explorar los conocimientos y las percepciones que tienen sobre el cáncer de mama las mujeres, destinatarias de los mensajes; y (3) describir y validar los mensajes de sensibilización, detección y tratamiento, los contenidos, la propuesta estética y los atributos identitarios de los mensajes producidos por el PNCM.

El equipo de Coordinación del PNCM tiene la experiencia de haber evaluado los mensajes del material gráfico Mitos y verdades sobre el cáncer de mama, que se actualiza constantemente, y la identidad visual del Programa en el estudio Aportes para la construcción de la identidad visual del Programa Nacional de Cáncer de Mama de Leticia Rivas (2013). Como antecedente también se tuvo en cuenta la investigación de TRAMA - Lazos para el desarrollo Comunicar el cáncer colorrectal: Estudios de recepción de mensajes informativos, de sensibilización y educativos del Programa Nacional de Prevención y Detección temprana del Cáncer Colorrectal (2017), y otras investigaciones vinculadas a los sentidos sociales sobre el cáncer, tales como el estudio de Marisa Ponce Mujeres y Salud; la prevención del cáncer de cuello del útero y el cáncer de mama en la Ciudad Autónoma de Buenos Aires (2010) y el estudio Imágenes Sociales del Cáncer (2013) realizado por el INC a través del Centro de Estudios de Estado y Sociedad (CEDES).

\section{Estrategia metodológica}

La propuesta metodológica para alcanzar estos objetivos consistió en un tipo de diseño exploratorio-descriptivo y en la utilización de un enfoque cualitativo. El tipo de muestra fue no probabilística. La selección de los materiales a validar se realizó de manera intencional de acuerdo con el criterio de que sean materiales informativo-comunicacionales gráficos. La selección se consensuó con el PNCM, y su intención fue validar un material gráfico en soporte de tríptico realizado durante 2018 y placas o flyers que forman parte de la campaña Octubre. Mes de la concientización del cáncer de mama y que circulan en la página de Facebook del INC. Se acordó también incorporar en la muestra el material gráfico impreso con formato de tríptico Cáncer de mama: La detección temprana aumenta las posibilidades de cura. El argumento principal por parte del equipo del PNCM para no validar otros materiales fue su falta de distribución y su desactualización.

Las técnicas de recolección de la información fueron (1) entrevistas semiestructuradas a integrantes del equipo de comunicación del INC y entrevistas semiestructuradas grupales a integrantes del equipo de Coordinación de PNCM; (2) análisis de documentos programáticos y materiales gráficos producidos y valorados por el PNCM; (3) grupos de discusión con mujeres mayores a 35 años. 
La secuencia metodológica consistió en dos momentos:

a. Análisis en producción. Se realizó el análisis de los materiales informativos/educativos gráficos a partir de la propuesta de ejes para el análisis y la construcción de mensajes educativos de Gabriel Kaplún (2002): el eje conceptual, pedagógico y comunicacional. El primer eje refiere a los contenidos, su selección y organización fundamentada en un diagnóstico de situación. El segundo eje implica un análisis de los objetivos pedagógicos (explícitos o no) y la caracterización de los destinatarios, incluyendo los supuestos en torno a sus ideas constructoras sobre las cuales, con las cuales y contra las cuales se intenta construir una nueva percepción, entre otros recursos didácticos. Por último, el tercer eje refiere a las figuras retóricas o poéticas, y en general a los modos concretos de relacionamiento con Ixs destinatarixs que propone el material, cómo son interpelados, cómo se recupera su lenguaje, sus consumos culturales y sus contextos de vida. Este análisis se complementó con entrevistas individuales y grupales a la encargada de comunicación del INC y al equipo técnico del PNCM.

b. Análisis en recepción. Se procedió a la realización de grupos de discusión a partir de la adaptación de diferentes guías de validación de materiales (TRAMA, 2014). Por tanto, se describieron y analizaron las siguientes dimensiones de los materiales de comunicación: (1) Objetivos de los materiales y relación con los objetivos programáticos; (2) Prefiguración de las audiencias; (3) Contenidos y estética (atracción, entendimiento, identificación e involucramiento, aceptación y propuesta de cambio o acción)

Se conformaron cuatro grupos de discusión integrados por siete a diez mujeres cada uno. Los criterios de selección para la conformación de los grupos fueron: (1) que sean mujeres, debido a que son las destinatarias de los mensajes producidos por el PNCM; (2) que se encuentren entre los 35 y 75 años de edad, ya que la edad recomendada para la realización de la mamografía es entre 50 y 69 años, y desde la Coordinación de PNCM se expresó la necesidad de incluir, además de este grupo objetivo, mujeres de menor y de mayor edad; (3) que sean de sectores populares, ya que desde el PNCM se cree que quienes más se encuentran afectadas por esta enfermedad, y quienes menos pueden acceder a la detección temprana son mujeres pertenecientes a este sector. Los indicadores tenidos en cuenta para el cumplimento de este criterio fueron el nivel de estudios (secundario incompleto); el tipo de trabajo (integrantes del Programa Hacemos Futuro, cooperativistas y jubiladas por amas de casa); el barrio (ubicados en las periferias de las ciudades); y la cobertura de salud (usuarias del sistema público de salud). En palabras del equipo de Coordinación del PNCM $<<$ todas las informaciones son 
válidas para nosotros, pero saber cómo interpreta nuestros mensajes esa mujer que tiene muchos menos recursos o posibilidades más limitadas, es mucho más rico>>.

El primer (G1) y el segundo grupo (G2) estuvieron integrados por mujeres de 35 a 55 años; el tercer (G3) y cuarto grupo (G4), por mujeres de 56 a 75 años. Los materiales gráficos digitales, fueron validados por el G1 y el G3; y el material gráfico impreso fue validado por el G2 y el G4, lo cual permitió que todos los materiales hayan sido validados por ambos grupos de edad.

Para el procesamiento y análisis de la información recolectada se apeló a la fragmentación de cada uno de los documentos (documentos programáticos como Guía programática abreviada Documento técnico para referentes del Programa; y guías como El cáncer de mama en 8 palabras - Una guía breve para la atención primaria de la salud y desgrabaciones de entrevistas y grupos de discusión) en unidades de codificación para su agrupamiento en las dimensiones o núcleos temáticos pertinentes para los objetivos de la investigación.

\section{Resultados}

\section{El proceso de producción}

El proceso de producción de materiales de comunicación de $\mathrm{CM}$ se realiza de manera interdisciplinaria, entre el área de Comunicación del INC y el equipo de Coordinación del PNCM. Si bien la demanda de la producción de un material puede surgir de diferentes actores intervinientes, el resultado final es compartido y aceptado por la totalidad del equipo.

El eje conceptual es definido conjuntamente entre el PNCM y el área de comunicación del INC. En relación específicamente a los materiales digitales validados en esta investigación, cuya distribución principal ocurre en la página de Facebook del INC, el proceso de producción está centrado principalmente en el área de comunicación. Como afirma Leticia Rivas, integrante del equipo de comunicación del INC, <<casi ni participó gente del Programa, más que nada se dio el producto terminado para que le den el okey. Pero responden a la línea de mensajes de materiales anteriores >>

En esta campaña, producida en 2018 durante el mes de Octubre (el mes de la concientización del cáncer de mama) se definieron 5 líneas de mensajes, expresados por Rivas como: (1) qué es el cancer; (2) la detección temprana; (3) la edad de riesgo, (4) la mamografía, el examen físico y el control; y (5) el acompañamiento. La organización del contenido se da de manera tal que la información más importante se encuentra en el diseño del flyer; este mensaje se profundiza y desarrolla en detalle en la descripción que acompaña al mismo en la red social. Por su parte, el material gráfico tríptico, responde según el equipo de Coordinación del PNCM a tres mensajes principales: (1) edad objetivo del tamizaje; (2) método: detección temprana y 
mamografía; y (3) síntomas y antecedentes. Con respecto al método, se opta por utilizar el concepto de detección temprana y focalizar en los estudios clínicos y la mamografía en vez de en prácticas preventivas. Como se afirma en la Guía Programática Breve:

\begin{abstract}
El CM es una enfermedad difícilmente prevenible. Se han identificado algunos factores de riesgo como la historia familiar, la exposición a estrógenos endógenos o exógenos, sobrepeso, ingesta moderada de alcohol, consumo de tabaco y sedentarismo. La modificación de estos factores requiere de un largo proceso de cambios culturales; este proceso recién se inicia en nuestra sociedad y sus efectos tardarán en evidenciarse varias décadas, por lo tanto, los esfuerzos para lograr el control de la enfermedad en el mediano plazo deben centrarse en la detección temprana y la implementación de tratamientos pertinentes (2014, p. 2).
\end{abstract}

A su vez, el equipo de Coordinación hace hincapié también en la edad objetivo del tamizaje recomendado por el PNCM ya que existen en la actualidad muchos organismos privados que realizan campañas comunicacionales que abordan esta enfermedad, y que proponen diversas edades para la realización del mismo.

Según Rivas, desde los inicios del PNCM existió la idea generalizada de que el CM es una enfermedad prevenible; por ello el propósito pedagógico clave del programa y de los materiales fue y sigue siendo instalar la mamografía como método de detección temprana a partir del cual se diagnostica el cáncer y se accede al tratamiento. Los objetivos de comunicación cuando se creó el PNCM eran principalmente informativos: edad de riesgo y métodos de detección temprana. Con el tiempo, se comenzaron a utilizar estrategias pedagógicas más en relación a la sensibilización y a la interpelación de las destinatarias retomando mitos y preconceptos acerca de la enfermedad de la población objetivo, para contradecirlos o aportar nuevas formas de concebir el cáncer de mama. La intención de los mensajes actualmente se dirige, según Rivas, a $<<$ no dramatizar y a no culpabilizar a la mujer con cáncer de mama $>>$, lo cual implica no poner el eje en la falta de realización de controles médicos por parte de la mujer, sino en la posibilidad de detección temprana y de curación. Esta es un sentimiento muy presente en las destinatarias y se intenta por ello construir una nueva percepción acerca de la enfermedad. Una de las estrategias de interpelación a nivel pedagógico presente en la producción de los materiales, según Rivas, es la de:

humanizar y mostrar otra cara sobre el cáncer de mama. El cáncer no es un tema tabú, pero sigue siendo un tema que a la gente no le interesa hablar. No es un tema lindo para ponerte a conversar porque se lo vincula con la muerte, con algo horrible. 
La incorporación de la idea del acompañamiento como algo fundamental durante el tratamiento también es una idea constructora que surge a partir de la escucha de mujeres usuarias del sistema público de salud y que plantean la importancia de no estar solas en dicho proceso. Como afirma Rivas:

ellas, que pasaron por el tratamiento, hicieron hincapié en que el acompañamiento tenía que estar. Una siempre piensa que lo único importante es la mamografía, la edad. Y la verdad es que hay un montón de cosas (...) una mujer que se informa también es importante que esté acompañada, también es importante cómo reacciona su familia, que pasa con su trabajo, entre otras cosas.

Más allá de los cambios ocurridos en el PNCM, el objetivo general de todo material, según la Coordinación de PNCM, siempre ha sido el mismo: <<vos partís de un objetivo que es reducir la mortalidad de CM y garantizar un diagnóstico y un tratamiento adecuado y oportuno para todas las pacientes. Todos los ejes programáticos y líneas de acción que hablamos van en esa línea>>.

Con respecto al eje comunicacional, la relación que se propone desde el PNCM con las destinatarias de los materiales, es, en palabras de Rivas, <<humana, sensible, cercana >>. Se intenta que el lenguaje corresponda al universo vocabular de las destinatarias, ya que:

si un médico escribe un material lo escribe tan técnico que no se llega entender. Todo hay que bajarlo mucho más al llano que lo que es. Porque si sos comunicador también entendés cosas complejas, pero tenés que ponerte en la cabeza de alguien que no sabe. Rivas

Involucrar a pacientes que sobrevivieron fue una de las formas de interpelación más utilizada en los materiales validados. La relación que se planteó fue la de incorporar la fotografía o la ilustración de una mujer, quien emite el mensaje principal y que, mediante éste, se dirige directamente a las destinatarias. Con respecto a las fotografías (tanto de los flyers como del tríptico), Rivas afirma que son mujeres que atravesaron el tratamiento y se encuentran actualmente sanas; esta decisión se argumentó de la siguiente manera: <<involucrar pacientes que sobrevivieron nos parece un mensaje súper alentador, le da un tono positivo, no catastrófico. El mensaje de que es posible curarse>>

Por otro lado, existe un esfuerzo por parte del equipo por incluir mujeres que califican como $<<$ reales >>, ya que como afirma Rivas, es importante que las mujeres destinatarias de los mensajes se identifiquen con el material de comunicación. Con respecto a los colores, en los materiales gráficos prevalece el color rosa, identificado como el color del cáncer de mama. En 
relación a las imágenes, Rivas afirma que utilizan ilustraciones y fotografías de mujeres cercanas a la edad de la población objetivo, y:

que no sea ni una mujer súper pobre, porque a veces hacen eso, algunas comunicaciones públicas apelan a ese tipo de perfil. Ni tampoco una mujer de alta alcurnia que por ahí ni mira el material. Ni flacas ni gordas, mujeres normales. Siempre buscamos una mujer cercana que puede ser tu tía, tu mamá o vos misma

Por otro lado, Rivas hace referencia a la importancia de la producción de materiales digitales:

el material gráfico va a seguir existiendo, tiene que estar, te lo piden y se usa, pero el fuerte tiene que estar en lo digital. Hay que encontrarle la vuelta para que el CM sea algo agradable, para que lo quieran seguir, más de marketing, mujeres famosas o algo así (...) Con el supuesto de que el mundo es digital, ya nadie mira el papel. Todo lo que la gente se informa, es a través del celular (...) hay que adaptarse a los tiempos, como si todo está yendo a un mundo que es digital hay que apostar ahí pero sin dejar de lado otros recursos que nosotros usamos que todavía se usan. Eso hay que indagar, hasta qué punto las personas siguen leyendo folletos

\section{Conocimientos y percepciones acerca del cáncer de mama}

Como ya se ha mencionado, la comunicación es un eje fundamental del PNCM, que se expresa a través de la producción de materiales y acciones de comunicación orientadas a sensibilizar e informar a las mujeres acerca del CM y su detección temprana. Se reafirma que esto es necesario pero no suficiente, ya que esta es problemática de salud que (al igual que otras) está signada por sentidos sociales que condicionan el control médico y funcionan como barreras de acceso en las mujeres.

En los grupos de discusión realizados, el CM resultó una enfermedad conocida por la totalidad de las mujeres, y la mayoría identificó la mamografía como método de control y detección. Sin embargo, apreciaciones negativas vinculadas a la muerte y motivos por los cuales no se realizan controles, como el miedo a diagnósticos positivos, fueron datos que otorgan relevancia y abren la posibilidad de pensar nuevas propuestas conceptuales no peyorativas en la revisión de los materiales existentes o en nuevos.

El cáncer de mama fue relacionado con un <<ganglio $>>,<<$ pelotita de grasa $>>,<<c o s o$ para afuera $>>$. También se afirma en casi todos los grupos que $<<$ es algo que tenés y se te despierta>>. Unas pocas, realizan estudios clínicos y mamografía periódicamente. En este sentido, encontramos supuestos en relación al método de detección temprana y a la búsqueda de explicaciones del CM (y algunos de ellos también son reconocidos como mitos usuales en el material del PNCM Mitos y verdades sobre el cáncer de mama) En relación al método, se

Question, Vol. 1, N. ${ }^{\circ}$ 65, abril 2020. ISSN 1669-6581

Instituto de Investigaciones en Comunicación | Facultad de Periodismo y Comunicación Social | Universidad Nacional de La Plata 
encuentra en todos los grupos el supuesto de que la mamografía causa dolor. Una de las mujeres que nunca se había realizado una mamografía, perteneciente al G3, comentaba que:

me dijeron que es doloroso e invasivo, porque esta señora que se operó me dijo que un día se la estaba haciendo y se desmayó del dolor. Entonces cuando una escucha eso $[\ldots]$ y una que ya viene con que no le gusta ir al médico.

En relación a la búsqueda de explicaciones sobre el cáncer de mama, se encuentran dos supuestos. Primero, la utilización de antitranspirantes: <<yo me ponía Rexona. No tengo nada de malo con las marcas, pero me afeitaba y me hizo un bulto. Te juro que pensé que era cáncer. Desde ahí que no uso más>> (G4).

Segundo, la más recurrente (y la que no aparece en Mitos y verdades sobre el cáncer de mama) es la que vincula los golpes en las mamas con el cáncer.

Varias mujeres compartieron graves casos de allegadas que derivaron en intervenciones médicas agresivas, en dolor y/o en la muerte. Expresaron visiones negativas sobre el cáncer: $<<y o$ te digo la verdad, cuando pienso que me puede llegar a pasar algo me dan ganas de morir. Por eso te digo, es preferible no ver a la enferma >> (G4). También se manifiesta una desconfianza hacia el personal médico, tanto para quienes se atienden regularmente, como para quienes no se atienden: <<yo soy un bicho raro. No voy al médico. Y no es por pereza, eh. Suponele que tengo resfrío, me duele la garganta. Yo no voy al médico, ¿para qué si tengo mi té de jengibre? >>(G3).

$Y$ otras mujeres que tampoco se han realizado nunca una mamografía, no asisten a los controles por falta de tiempo o de ganas: <<yo voy al hospital cuando es una urgencia, si no es una urgencia olvidate que vaya. $Y$ si tengo que acompañar a alguien, no lo acompaño. Corta >>; $<<A y$ yo soy igual, a mi no me gusta tampoco. Por ahí vas y te estás muriendo y son doscientas horas. Es un tiempo también>> (G2)

Otra de las causas y de los sentimientos que aparecen alrededor de esta enfermedad, es el miedo: <<a veces pensamos que las cosas pasan porque estamos preocupadas por prevenirlas, pero no, las cosas pasan por otras cosas $>>(G 4) ;<<$ yo pienso que uno en el fondo tiene miedo. Si me sale algo mejor no me entero, en el fondo, esa resistencia tiene que ver con eso>> (G3)

\section{Materiales}

El análisis de los materiales de comunicación del PNCM constituye una instancia significativa para analizar a la población objetivo; en qué medida se otorga información verídica; y en qué 
medida se instalan sentidos más favorables a la detección del CM. Con respecto a la validación realizada, los hallazgos más útiles para revisar los materiales gráficos fueron, en primer lugar, la escasa identificación e involucramiento de las consultadas con las mujeres fotografiadas e ilustradas en los materiales digitales e impresos. A pesar de la intención por parte del PNCM de buscar la identificación con destinatarias similares a las del grupo, esto no se logra por diversos motivos: por la pertenencia social, la vestimenta, el lugar de residencia o el color de piel. Las calificaciones utilizadas por las mujeres son las de <<cheta $>>$; <<una modelo a la que le pagan, que posa. No es una señora como yo >> (G3); <<una actriz, como gente como ponen en todas partes, una gente conocida. Yo quiero una gente común, de barrio >> (G1); <<parecieran que son famosas. Son de alta sociedad $>>;<<$ Son todas de alta categoría. Y no hay una mujer joven >> (G2). Uno de los factores que condiciona la no identificación es la vestimenta, en este caso, ya que <<es más como de una oficina ella o algo así. Tiene que ser como más sencilla. Con alguna ropa deportiva o en vez de ponerle así como le ponen de traje pueden ponerle otra cosa >> (G1); <<es claro por la apariencia, el peinado, la vestimenta, que estén arregladas, teñidas. ¡Con lo que sale mantener la tintura! >>; <<son todas ejecutivas, no son de barrio >>; <<esa publicidad no se parece a nosotras del barrio. Queremos nuestras caritas acá>> (G2)

A su vez, se hizo alusión a la importancia de la diversidad cultural y la presencia de distintos tonos de piel en las imágenes, alegando que <<son todas blancas >>; que es importante <<el tema del tono de piel, habría que poner varios. Que pongan una morocha, colorada también>> (G1); o que es necesario preguntarnos<<iPor qué no una persona morocha? ¡Eso es una violencia mediática! no son de pueblo>> (G2). En los grupos también se hizo referencia al lugar de residencia como un aspecto clave:

\begin{abstract}
A mí me parece que el problema de la comunicación en general es que se dirigen a la capital. Estamos hablando de La Plata acá. Somos la capital de la provincia. Pero yo soy de Corrientes. Yo tengo mis familiares allá. Yo no la veo a mi sobrina que tenga un acceso directo a esto. Entonces [...] vos tenés que representarte el país, provincias, lugares de provincias. Me parece que el mensaje como es un mensaje del Ministerio de Salud de la Nación hay que hacerlo como más accesible en general (G44).
\end{abstract}

En segundo lugar, se identificaron incomprensiones de palabras relevantes en los mensajes, como tamizaje o textura; en signos como el hashtag, presente en la totalidad de los flyers validados; y en la diferenciación conceptual entre prevención y detección temprana, y entre examen físico y mamografía. Se identificó también que en la mayoría de los casos la relación explícita y directa entre el texto y la imagen, por un lado, se valora positivamente; y por otro, contribuye a la comprensión integral del mensaje, de forma más rápida y efectiva. En este sentido, se encuentra un amplio acuerdo en los grupos sobre la valoración positiva de los 
dibujos secuenciados sobre cómo realizarse un examen físico, ya que éstos ayudan mucho a comprender el paso a paso de este examen. También se sugiere la importancia de que en las fotografías se muestre a las mujeres yendo al consultorio médico o realizándose una mamografía, en los materiales donde el mensaje principal es el control y la realización de estudios; o se muestre a la mujer rodeada de otras personas y no sola, en el material donde el mensaje principal es el acompañamiento.

Con respecto a la atracción, se identificaron fuertes críticas a la longitud del texto escrito de los materiales y se propuso hacer más visible la oración cáncer de mama y al INC -institución desconocida por la totalidad de las mujeres consultadas- como productor del mensaje, a la hora de jerarquizar la información a través de resaltados o de cambios en el tamaño de las tipografías. Se considera la posibilidad de que el texto esté organizado en palabras clave que sinteticen las principales ideas y conceptos del mensaje: <<yo pondría frases sueltas como hacete la mamografía, Palpate las mamas, y el cáncer se cura, como para no decir toda la mala y que te quede lo más importante>> (G2)

En relación a la estética, se considera que las figuras geométricas que presenta el material no ayudan a comprender que se está haciendo referencia al cáncer de mama, y se la vincula en el G1 con la estética de revistas de venta de maquillajes. En otro grupo (G4), mientras tanto, decían que <<estaría bueno que haya dibujitos. Hay muchos folletos así. Para explicar los síntomas >> En la totalidad de los grupos se sugirió que el lazo rosa contribuiría a la identificación más rápida y efectiva del tema que aborda el material, ya que para ellas es la imagen representativa de la enfermedad; y el rosa es considerado para ellas el color representativo de la mujer.

Con respecto a los principales mensajes, se coincidió ampliamente en la inclusión de la importancia de la realización de estudios y del acompañamiento en el tratamiento de curación de la enfermedad. Afirman que muchas de las mujeres que tuvieron o tienen cáncer de mama <<sufren en silencio>> G2 o eligen <<tragarse la enfermedad solas >>. Se considera también que la mujer debería estar acompañada por familiares o amigos en las imágenes, para reforzar el mensaje el acompañamiento. Sin embargo, a muchas de las mujeres (G1 y G3) no les parece coherente con el mensaje la expresión de las mujeres fotografiadas, debido a que el tránsito por la enfermedad no debería mostrarse como un momento feliz; mientras que a otras (G2) les parece que no mostrar a la mujer triste es un mensaje alentador y positivo.

La inducción a la acción de los materiales es clara, pero aun así es necesario para las consultadas incluir un número telefónico de referencia para consultas, o de espacios públicos de salud en donde se pueden realizar los estudios médicos pertinentes, ya que $<<$ no te dice donde vos tenés que ir a practicarte eso>> (G3)

Question, Vol. 1, N. ${ }^{\circ} 65$, abril 2020. ISSN 1669-6581

Instituto de Investigaciones en Comunicación | Facultad de Periodismo y Comunicación Social | Universidad Nacional de La Plata La Plata | Buenos Aires | Argentina

Página 12 de 15 
Finalmente, los resultados de la investigación arrojan datos para cuestionar la priorización de los mensajes digitales, entendiendo que el CM es una enfermedad cuya población de riesgo son mujeres adultas y mayores, principalmente de sectores populares y que las competencias tecnológicas en este grupo de edad y en este sector, disminuyen considerablemente. Consideran que no es estratégico, dado que las personas de más edad no manejan las redes sociales (de hecho ninguna de las presentes en el G3 y el G4 lo hacía). Allí afirmaban que:

Es según a quien te dirigís. Ahora Ixs jóvenes no, por más que sean humildes tienen su celu, lo manejan, todxs se manejan con las redes. Pero si me hablás de alguien grande, bueno...las personas grandes se manejan con el televisor (G4)

Y que:

La televisión es otra cosa. Eso lo hace la gente más joven. Y de otro rango de plata, digamos. Yo mis amigas de acá de La Plata por ahí tienen un celular de esos. Pero no pienso en una señora bien doña, Doña Egidia por ejemplo. Y esto de Facebook, estamos hablando gente de 50, 70. ¿Cuántas personas de esa edad utilizan esa página? (G3)

Quienes sí manejaban internet y redes sociales (G1 y G2), comentaban que aun sabiendo su funcionamiento <<en Facebook ni lo ves, viste que pasás con el dedo y se te pasa todo>>; en cambio <<en papel ya te queda. No lo leés en el momento, pero por ahí lo encontrás en el bolso o estás en el baño y lo leés después>> (G2) En estos grupos se afirmó que, en el caso de leer y prestar atención en redes sociales a estos afiches, se les pondría like o me gusta.

\section{Conclusiones}

A pesar de la intención por parte del PNCM de buscar la identificación con destinatarias similares a las del grupo, esto no se logra por diversos motivos: la pertenencia social, la vestimenta, el lugar de residencia o el color de piel de las mujeres fotografiadas o ilustradas en los materiales validados. Se recomienda entonces que los materiales de comunicación del PNCM profundicen su enfoque de derechos y que los contenidos sean trabajados desde una mirada crítica de la discriminación y la exclusión surgida a partir de distinciones de género, de etnia o de diversidad sexual en cruce con la desigualdad política y económica. El enfoque intercultural es fundamental en este sentido, ya que $<<$ permite abrir espacios de diálogo donde cada grupo implicado pueda tomar cartas en los asuntos y problemas que lo afecten>>. La contemplación de la diversidad implica, por un lado, la preservación y promoción de culturas existentes y, por otro, la apertura a otras culturas (Acha et al, 2017) teniendo como premisa el 
respeto, la alteridad, la escucha, la inclusión de diversos modos de vida, sistemas de valores, tradiciones y creencias., aunque sin desconocer las posiciones desiguales de las mismas.

Será necesario también desarrollar materiales más concisos y claros, con gran prevalencia de imágenes, preferentemente fotografías, que refuercen el contenido escrito de manera explícita, ya que la relación directa entre el texto y la imagen, se valoró positivamente y se demostró que contribuye a la comprensión integral del mensaje, de forma más rápida y efectiva.

Finalmente, los resultados de la investigación arrojan datos para cuestionar la priorización de los mensajes digitales enunciados por el área de comunicación del PNCM, entendiendo que el $\mathrm{CM}$ es una enfermedad cuya población de riesgo son mujeres adultas y mayores, principalmente de sectores populares y que las competencias tecnológicas en este grupo de edad y en este sector, disminuyen considerablemente.

Queda pendiente, como futuras líneas de investigación, indagar en el rol de los equipos de salud en tanto comunicadores y educadores en las relaciones interpersonales con las mujeres que asisten a los centros de salud y en la formación de recursos humanos.

\section{Agradecimientos}

Especiales agradecimientos a todo el equipo del PNCM y al equipo de comunicación del INC por permitirme realizar este estudio de manera libre y en el marco de un vínculo de confianza, otorgándome los recursos necesarios para la realización la misma. También a las mujeres pertenecientes al Bachillerato Mansión Obrera, al Centro de Adultos Mayores, al Club El Carmen y al Centro de jubiladas de Berisso por contarnos sus opiniones y sus historias en relación al CM contribuyendo enormemente a los resultados de esta investigación

\section{Referencias bibliográficas}

Acha, M. Becerro, V. Bruno, D. \& lotti, A. Enfoque de derechos humanos, géneros e interculturalidad; en Planificación y comunicación: perspectivas, abordajes y herramientas. Compilado por Daniela Bruno y Flavia Demonte. $1^{\underline{a}}$ edición para el alumno. Facultad de Periodismo y Comunicación Social, La Plata. 2017

Kaplún G. Contenidos, itinerarios y juegos: Tres ejes para el análisis y la construcción de mensajes educativos, VI Congreso de ALAIC - Asociación Latinoamericana de Investigadores de la Comunicación, Bolivia; 2002.

Instituto Nacional del Cáncer. Imágenes sociales del cáncer: Estudio nacional para orientar la comunicación social. 1a edición, Buenos Aires. 2013 
Ministerio de Salud de la Nación. Guía Programática Abreviada: Programa Nacional del Cáncer de Mama. Ministerio de Salud de la Nación. 2014

Ministerio de Salud de la Nación. Cáncer de mama en Argentina: organización, cobertura y calidad de las acciones de prevención y control. Diagnóstico de situación del Programa Nacional y Programas Provinciales. Buenos Aires: Ministerio de Salud de la Nación; 2010.

Ponce, M. Mujeres y Salud; la prevención del cáncer de cuello del útero y el cáncer de mama en la Ciudad Autónoma de Buenos Aires. Universidad de Buenos Aires, Buenos Aires. 2010

Rivas, L. Aportes para la construcción de la identidad visual del Programa Nacional de Cáncer de Mama. $1^{\underline{a}}$ edición. Ciudad Autónoma de Buenos Aires, Universidad de Buenos Aires. 2013

TRAMA - Lazos para el desarrollo. Producción de materiales de comunicación y educación popular. Buenos Aires; Departamento de Publicaciones de la Facultad de Derecho y Ciencias Sociales de la UBA; 2014.

TRAMA - Lazos para el desarrollo. Comunicar el cáncer colorrectal: estudio de recepción de mensajes informativos, de sensibilización y educativos del Programa Nacional de Prevención y Detección Temprana del Cáncer Colorrectal. 2017 